\title{
(6) OPEN ACCESS \\ CASE REPORT \\ Delivering patient-centred care in rural family practice: using the patient's concept of health to guide treatment
}

\author{
Jennifer M Charlesworth, ${ }^{1}$ Evelyn McManus ${ }^{2}$
}

'Department of Medicine, National University of Ireland-Galway, Co. Galway, Ireland

${ }^{2}$ Department of General Practice, National University of Ireland-Galway, Co. Galway, Ireland

\section{Correspondence to} Jennifer M Charlesworth, charlesworth.jennifer@gmail. com

Accepted 10 December 2016

\section{SUMMARY}

Through an examination of the life of an 83-year-old patient diagnosed clinically with secondary progressive multiple sclerosis (MS), general practice specialists, consultants and junior doctors will see the importance of assessing their patient's concept of health and how to use this understanding to target healthcare options within their healthcare system. This article highlights, in a resource limited context of rural family practice, the utility of a strong physician-patient relationship, recalls the definition of patient-centred care, and the role of judicious inaction in certain contexts. These lessons can be extrapolated for use in more resource rich or specialised settings such as academic hospitals throughout Europe.

\section{BACKGROUND}

General practitioners (GPs) need to think differently from specialists according to Ian McWhinney, the late British GP and forefather of the discipline of family medicine. ${ }^{1-3}$ Unlike hospital medicine, the family physician:

1. Treats individuals not diseases

2. Works in the context of a trusted long-term relationship

3. Treats the patient holistically (organismally)

4. Provides treatment without the segregation of mind and body seen in other disciplines ${ }^{1}$

A GP is in a unique position to take into account the personal concepts of health and social context that impacts the health of their patients. GPs in rural under-serviced areas often independently manage complex medical conditions that are impacted by psychosocial and resource challenges. They must make compromises in order to provide the best patient-centred care $^{3-5}$ in the patient's (not the doctor's) cognitive framework. ${ }^{3-7}$ As we follow the journey of an 83-year-old patient with multiple sclerosis (MS) who lives alone in rural Ireland, we will attempt to illustrate her clinical diagnosis, understand her concept of health and identify ways her GP has targeted her care with action and inaction within the available healthcare system.

\section{CASE PRESENTATION}

\section{History (retrospective)}

An 83-year-old female patient presented to a rural general practice physician in the north of the republic of Ireland in 1954 with a 13-year history of extreme fatigue, and multiple episodes of transient subacute sensory and motor neurological dysfunction disseminated in time and space. Patient recollection noted that the neurological dysfunction manifested as transient lower and upper limb sensory loss ('the limb would go dead'), evolving into sensory and motor loss ('one leg would drag behind as I biked into town') occurring without warning and with varying anatomical distributions of the limbs both unilaterally and bilaterally ('at times, I could not stand up at mass for the gospel'). At presentation, she had no significant medical or family history other than fatigue that interfered with her farm chores and headaches in school as a girl. She denied eye symptoms and tremor, bowel and bladder symptoms at that time. The original neurological examination records are not available, but the patient recalls a thorough neurological evaluation with no specific findings at that time.

\section{Neurological examination (2014)}

The patient was examined by the first author in her home in 2014. She was awake, alert and comfortable sitting on the seat of a 4-wheeled walker. She ambulates in a seated position using her lower limbs to propel the walker. Examination of the cranial nerves was unremarkable. Visual acuity was tested with hand motions. The patient was able to read. Corneal reflexes were not tested for patient comfort. The patient's gait was not assessed as the patient was unwilling to ambulate. The examination of the patient's cognition, upper and lower limbs and cerebellum were also unremarkable, while proximal muscle weakness was described; it was not evident on physical examination. Her mood was euthymic and congruent throughout.

\section{DIFFERENTIAL DIAGNOSIS}

1. Clinically isolated syndromes suggestive of MS

2. Peripheral polyneuropathy
A. Vitamin $B_{12}$ deficiency
B. Diabetes mellitus
C. Inclusion body myositis

3. Infections

A. Neurosyphyllis

B. Leprosy

4. Compressive spinal cord lesions

5. Acute disseminated encephalomyelitis

\section{MULTIPLE SCLEROSIS}

MS is a chronic inflammatory demyelinating disease of the central nervous system (CNS) with prevalence of 289 per 100000 population in UK general practice. ${ }^{8-10}$ It has higher rates in women 
and Northern regions. ${ }^{11}$ Its aetiology remains unknown but is hypothesised to be due to the interaction of genetic susceptibility with predisposing environmental or viral inciting factors. ${ }^{8} 12$ Clinically it is divided up into a relapsing and remitting course (RR-MS) and primary progressive course (PP-MS) which does not see the same return of function after acute episodes. ${ }^{10}$ Eventually RR-MS will convert into a secondary progressive MS where you do not see return of function, and where treatments are moderately effective at best. ${ }^{10}$ This is clinically the current stage of the patient's disease.

MS is a clinical diagnosis with investigations to support. ${ }^{13-15}$ While it is difficult to imagine a modern patient diagnosed with MS without the use of imaging or supporting laboratory values, MRI technology was not available outside the theoretical sphere until the 1970 s. ${ }^{16}$ The slow stepwise progression of the disease over 60 years is also consistent with this diagnosis. While MS in childhood is rare, headaches are not unheard of as part of a presenting constellation of features such as fatigue. ${ }^{17} 18$ The evolution of symptoms leading to the patient's clinical diagnosis at age 23, illustrates the classic evolution of MS meeting clinically likely diagnostic criteria $^{19}$ : a young adult woman (1) who experienced multiple episodes of clinical white matter (2) CNS dysfunction (3) in multiple anatomic locations (4) separated in time and space (5), with no better explanation (6). We note likely versus definite as without some investigation and documentation of neurological examination at the time, peripheral polyneuropathy and infection cannot be completely discounted.

Nevertheless, the clinical progression to date, resulting in urine incontinence, history of heat intolerance (Uhthoff phenomenon) at presentation causing exacerbation of symptoms during exertion, combined with progressive optic pathology (although never formally examined) presents a convincing clinical argument to support a diagnosis of MS.

\section{PATIENT'S PERSPECTIVE}

Her 'fragility' was finally explained almost 60 years ago, when she was diagnosed with MS by a GP in the community. Since then, she has coped well with her illness, accepting all help that can be provided to her within her home and community by her rural GP. As the disease progressed, the patient finds herself more and more debilitated, welcoming further medical services and home care as available and necessary, but avoiding advanced secondary care that might assist particularly with the visual concerns. Why? What is patient-centred care in this situation? To understand, let us explore the patient's concept of health:

A farmer's daughter, the patient, and her three siblings come from modest stock. 'I was not as strong as I should be', but there was 'nothing really I could do. When I got really tired, I rested a wee while and then (got) going again'. 'I used to cycle a lot to (town)'. However, doing this, she still 'felt the journey took a whole lot of my energy away'. 'I used to go out, but it would upset me. (Now) going out is too much, it is a wile worry'.

However, the patient is delighted for the social company that is available at home. Today she misses her brother not only as a sibling but as 'he was great company to me'. She welcomes her rural GP and reaches out whenever she has need of supportive services or prescriptions and is grateful for the home visits that can sometimes be provided. She is glad to have the students over to help them learn and give back, and she is comfortable saying when she is tired or in need of a break. Here, in her own environment, and despite her inability to get into the bed or toilet independently, she is content to accept any and all care that is available.

\section{TREATMENT}

In the 1950 s, MS was thought to result from limited blood flow. Treatments based on this cutting edge science, were not available outside the academic centres and certainly not in rural Irish town. ${ }^{16}$ Thus, initially, no treatment was provided to the patient aside from X-rays (new technology at the time which might have had a therapeutic benefit). Improved health was seen between what is presumed to be inflammatory episodes, which eventually took much of her sight, bladder control and ability to ambulate without the aid of a wheelchair. During this time the patient had numerous falls associated with balance and weakness including three short hospitalisations (hospital records unavailable-no documented MRI or intravenous steroids) for associated fractures and trauma. Each time the patient found these environments so distressing she left as soon as possible, and often against medical advice. By 1978, intravenous steroids were in use to treat exacerbations, and by 1990 biologics were available in some parts of the world with success in preventing some neurological decline; however, in rural Ireland these were only administered in hospitals. ${ }^{20}$

The patient's concept of health is 'anything that can be carried out within her home and community', care by her GP has consisted of supportive care within this context. She takes medication for symptom management (eg, tolteridine for bladder and amantadine for fatigue), takes advantage of all the home care the state can provide and would accept more if the Heath Service Executive (equivalent to the NHS) would approve it. The patient welcomes and seeks out her GP for any assistance that can be provided on home visits. She declines healthcare outside of this environment, such as a neurological specialist or hospitalised treatment of relapse, because it falls outside of her concept of health.

\section{OUTCOME AND FOLLOW-UP}

\section{Patient-centred care: using the patient's concept of health} to target treatment

As GPs, our cognitive bias tells us that in this case, the GP would ideally serve as a team-lead and coordinator, a health advocate and support for the patient facilitating access to every possible specialised resource available to manage MS. For this patient, the GP uses this patient's concept of health to streamline her efforts and treats her patient effectively and efficiently using the concept of 'judicious inaction'. She provides supportive care and directs access to home help. The patient is thrilled her GP coordinates home support and care, provides home health visits when necessary and prescriptions for symptomatic management. Her current GP only attempts to coordinate secondary care when absolutely necessary (ie, in the case of a fall) as ultimately, this care is outside the patient's personal concept of health. Previously practitioners attempted care outside the patient's concept of health and the patient will cancel or miss any appointments made for her outside her home and community. She will not accept help from her GP removing barriers for her to access secondary care services as these services available outside her community fall outside her concept of health.

A clinician can feel helpless and ineffective when their patient declines offers to go to hospital to get treatment for a flare-up or a cardiac condition as is medically indicated. However, by going back to the organismal view of the patient in a long-term continuing relationship noted by McWhinney, ${ }^{1-5} 721$ it should become clear to trainees and experienced clinicians alike why this sort of care would not be, in this case, patient-centred. In terms of maximising patient-centred healthcare, the real role for 
the physician is more that of a communicator of options, collaborator in creating the patient's vision of health and a professional caring for the patient in her beloved home.

One might then ask why this approach was not taken initially as this patient has been in the system for 60 years. The answer is evident when one considers this case is being discussed with the accuracy of hindsight. Like many problems in medicine, it is often a GPs biggest challenge to identify a patient's true concept of health. In this case, as is often the case, the current understanding of this patient's concept of health was developed over time by trial and error as a product of multiple discussions had over the course of the longitudinal therapeutic relationship.

This patient and her story illustrates a clinical diagnosis of MS, elicits understanding of how the patient's concept of health enables more targeted healthcare, and provides perspective on why patients might reject treatment that is intended for their benefit. Finally, this case supports the ideal of targeted options and discussion within both the patient's concept of health and the healthcare system as a way to develop the clinician-patient relationship and improve on professional efficiency. 'Judicious inaction' need not be viewed as neglect but can be considered a part of patient-centred care.

\section{CONCLUSION}

\section{Lessons for the developing trainee}

This case highlights that some neurological diagnoses, including MS, are clinical. It reinforces to all physicians and particularly GPs the importance of assessing their patient's concept of health and how to use this understanding to target healthcare options within their healthcare system. Through a discussion of the patients long-term relationship with her GP, her disease progression and the current outcome; this article demonstrates the utility of a strong physician-patient relationship in providing patient-centred care and highlights advantages of judicious inaction within these contexts.

\section{Learning points}

- Multiple sclerosis (MS) is primarily a clinical diagnosis.

- It is important for all healthcare providers particularly general practitioners to assess their patient's concept of health.

- Clinicians should use this concept of health to target healthcare options within their healthcare system.

- Appropriate care can sometimes be exemplified by 'judicious inaction' in certain contexts.

Acknowledgements Professor AW Murphy; Professor P Cantillon; Dr P Hayes; Dr B Callaghan; Dr Liam Bannan; Dr Clarissa Moodie, Medical Editor; Ms Gillian McGlinchey; Ms Myriam Davidson; Ms Jennifer Lay; The staff at the patient's health centre.
Contributors JMC performed the data acquisition, analysis, and interpretation of data for the work with oversight from EM. Both authors made substantial contributions to the conception and design of the work. Both authors were involved in the drafting (JMC) and revising of the work (EM and JMC). JMC and EM gave final approval of the version to be published. JMC and EM are in agreement to be accountable for all aspects of the work in ensuring that questions related to the accuracy or integrity of any part of the work are appropriately investigated and resolved.

Competing interests None declared.

Patient consent Obtained.

Provenance and peer review Not commissioned; externally peer reviewed.

Open Access This is an Open Access article distributed in accordance with the Creative Commons Attribution Non Commercial (CC BY-NC 4.0) license, which permits others to distribute, remix, adapt, build upon this work non-commercially, and license their derivative works on different terms, provided the original work is properly cited and the use is non-commercial. See: http://creativecommons.org/ licenses/by-nc/4.0/

\section{REFERENCES}

1 McWhinney IR. The importance of being different. Part 1: the marginal status of family medicine. Can Fam Physician 1997;43:193-5, 203-5.

2 McWhinney IR. William Pickles Lecture 1996. The importance of being different. Br J Gen Pract 1996;46:433-6.

3 Levenstein JH, McCracken EC, McWhinney IR, et al. The patient-centred clinical method. 1. A model for the doctor-patient interaction in family medicine. Fam Pract 1986;3:24-30.

4 Brown J, Stewart M, McCracken E, et al. The patient-centred clinical method. 2. Definition and application. Fam Prac 1986;3:75-9.

5 Stewart M, Brown J, Levenstein J, et al. The patient-centred clinical method. 3. Changes in residents' performance over two months of training. Fam Prac 1986;3:164-7.

6 Eyssen IC, Dekker J, de Groot V, et al. Client-centred therapy in multiple sclerosis: more intensive diagnostic evaluation and less intensive treatment. J Rehabil Med 2014;46:527-31.

7 Pimlott N. Reflecting on Dr lan McWhinney. Can Fam Physician. Canada. 2012;58:1187-8.

8 Mackenzie IS, Morant SV, Bloomfield GA, et al. Incidence and prevalence of multiple sclerosis in the UK 1990-2010: a descriptive study in the General Practice Research Database. J Neurol Neurosurg Psychiatry 2014;85:76-84.

9 Amtmann D, Askew RL, Kim J, et al. Pain affects depression through anxiety, fatigue, and sleep in multiple sclerosis. Rehabil Psychol 2015;60:81-90.

10 Confavreux C, Vukusic S. The clinical course of multiple sclerosis. Handb Clin Neurol 2014;122:343-69.

11 Fogarty E, Walsh C, McGuigan C, et al. Direct and indirect economic consequences of multiple sclerosis in Ireland. Appl Health Econ Health Policy 2014;12:635-45.

12 Methley AM, Chew-Graham C, Campbell S, et al. Experiences of UK healthcare services for people with multiple sclerosis: a systematic narrative review. Health Expect 2015;18:1844-55.

13 Perry M, Swain S, Kemmis-Betty S, et al., Guideline Development Group of the National Institute for Health and Care Excellence. Multiple sclerosis: summary of NICE guidance. BMJ 2014;349:95701.

14 Rolak LA. The diagnosis of multiple sclerosis. Neurol Clin 1996;14:27-43.

15 Rolak LA, Fleming JO. The differential diagnosis of multiple sclerosis. Neurologist 2007;13:57-72.

16 Rolak LA. The history of MS. ed N M Society. National MS Society, 2016.

17 Evans RW, Rolak LA. Migraine versus multiple sclerosis. Headache 2001;41:97-8.

18 Absoud M, Cummins C, Chong WK, et al. Paediatric UK demyelinating disease longitudinal study (PUDDLS). BMC Pediatr 2011;11:68.

19 Polman $\mathrm{CH}$, Reingold SC, Banwell B, et al. Diagnostic criteria for multiple sclerosis: 2010 revisions to the McDonald criteria. Ann Neurol 2011;69:292-302.

20 Rolak LA. Multiple sclerosis treatment 2001. Neurol Clin 2001;19:107-18.

21 McWhinney IR. Response to thoughts on the importance of being different. Can Fam Physician 1997;43:1208-9. 
Copyright 2017 BMJ Publishing Group. All rights reserved. For permission to reuse any of this content visit http://group.bmj.com/group/rights-licensing/permissions.

BMJ Case Report Fellows may re-use this article for personal use and teaching without any further permission.

Become a Fellow of BMJ Case Reports today and you can:

- Submit as many cases as you like

- Enjoy fast sympathetic peer review and rapid publication of accepted articles

- Access all the published articles

- Re-use any of the published material for personal use and teaching without further permission

For information on Institutional Fellowships contact consortiasales@bmjgroup.com

Visit casereports.bmj.com for more articles like this and to become a Fellow 